\section{Swedish Society for Physical Activity and Sports Medicine: a long history of excellence in sport and exercise medicine}

\author{
Magnus Forssblad, ${ }^{1}$ Karim Khan ${ }^{2}$
}

Kudos to Sweden for its 11 medals at the Summer Olympic Games. From the comfort of the BJSM media centre in Vancouver, Sweden was first prominent via triple (and full set) swimming medalist, freestyle and butterfly swimmer Sarah Sjostrom. A big story in the middle of the Games was Sweden giving the US women's football team marching orders in a penalty shoot-out. No-one who saw it will forget Lisa Dahlkvist's ice-cool head (and smile) as she waited to take the match-winning penalty, while the opposing goalie delayed the moment of truth with some essential glove repair work. Whistle! BOOM! Goal!

And speaking of fearless, sangfroid, Sweden showed bike wizardry to medal on the road and in the mountain (Emma Johansson and Jenny Rissveds). BJSM commends all the SFAIM (Swedish Society for Physical Activity and Sports Medicine) for providing athletes with quality care all year around-not just for 17 days while the world tunes in.

The second biggest annual prize for medicine has just been awarded to Japan's professor Yoshinori Ohsumi for discovering autophagy. Congratulations, and it seems to pave the way for mechanotherapy and apoptosis to be right in the focus of the Nobel committee for 2017. The first biggest prize is of course the Nordic Medical Prize and Sweden's winner was Professor Jon Karlsson (http://www.akademiliv. se/en/2015/11/29614/). He shared with Lars Engebretsen, Roald Bahr and Michael Kjaer. Did Mozart write the Genius Quartet with these clinicians in mind? We had hoped to feature the Nordic Medical Prize as a BJSM cover (figure 1), but the pressure of having 23 member societies did not give us a spare cover. We will have to kick one or two out to make room for the Editors' creativity. Or not.

\section{SCANDINAVIAN ADVANCES AND CONGRESS IN NOREFJELL}

This issue highlights the strength of Scandinavian research. Danish researchers are

\footnotetext{
${ }^{1}$ President of the Swedish Association for Physical Activity and Sports Medicine and Stockholm Sports Trauma Research Center, Karolinska Institutet, Stockholm, Sweden; ${ }^{2}$ British Journal of Sports Medicine, University of British Columbia, Vancouver, British Columbia, Canada

Correspondence to Dr Karim Khan, President of the Swedish Association for Physical Activity and Sports Medicine and Stockholm Sports Trauma Research Center, Karolinska Institutet, UBC, Centre for Hip Health and Mobility, Vancouver, BC, Canada V6T 1Z3; karim.khan@ubc.ca
}

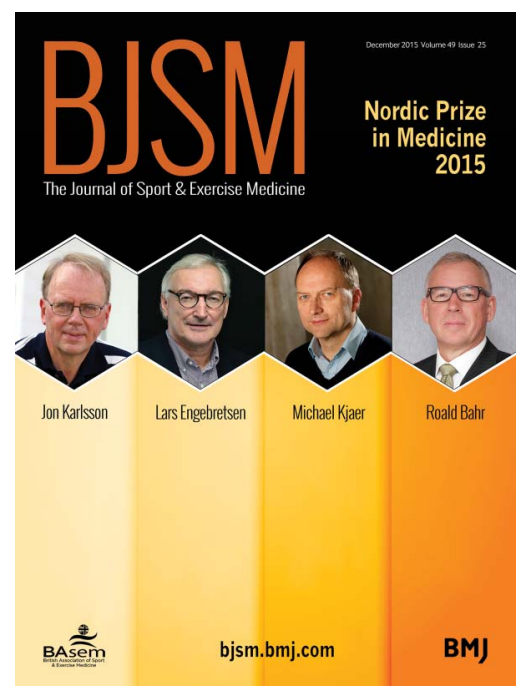

Figure 1 Winners of the Nordic Medical Prize from left to right on the mock coverJon Karlsson (Sweden), Lars Engebretsen (Norway), Micheal Kjaer (Denmark), Roald Bahr (Norway).

prominent with a major study of the risk of sitting and its association with Type 2 diabetes mellitus (fixable!) (see page 1382). We also publish a simple review of Diabetes Guidelines around the world (see page 1379). It is an example of what can readily be performed in various conditions-stronger together (more able to argue to policymakers).

At the younger age spectrum, our colleagues in Copenhagen, including Professor Jens Bangsbo, highlight the benefit of the 'FIFA 11 for Health' (see page 1394). From Finland, an epidemiological study of Women's International Ice Hockey at the very highest level (see page 1406). Our 2016 Swedish meeting keynote speaker, Professor Jon Drezner, argues for the benefits of cardiac screening (see page 1376). See last year's Swedish issue for Mats Borjesson's take along those lines. ${ }^{1}$ These are important debates and Drezner strongly rebuts the push by Van Brabandt ${ }^{2}$ (in The BMJ) that screening may be futile. Also from USA, at a time when all eyes will be on the election booths, the extraordinary talented Professor Chad Cook explains why we have a long way to go before we can predict injury accurately (see page 1356). This seems to be a hot topic right now ${ }^{3}$ and we imagine it will not be resolved until the keynote on that topic in Monaco, 16-18 March 2017 (http://www. ioc-preventionconference.org/)
THE SWEDISH ANNUAL MEETING: PLAN NOW FOR 2017!

As the nights get longer in the Northern Hemisphere, you can already anticipate the spring. There is nowhere better than Umeå in 11-13 May 2017 (figure 2). Long, long days to celebrate the best of Swedish sportsmedicine. Brilliant keynote speakers for Umeå are:

- Professor Roman Seil, from Luxemburg, the President of the European Society for Sports Traumatology, Knee Surgery and Arthroscopy (ESSKA)

- Professor Neil Armstrong, Exeter University, Children's Health and Exercise Centre

- Professor Ulf Ekelund, Norwegian School of Sport Sciences (NIH)

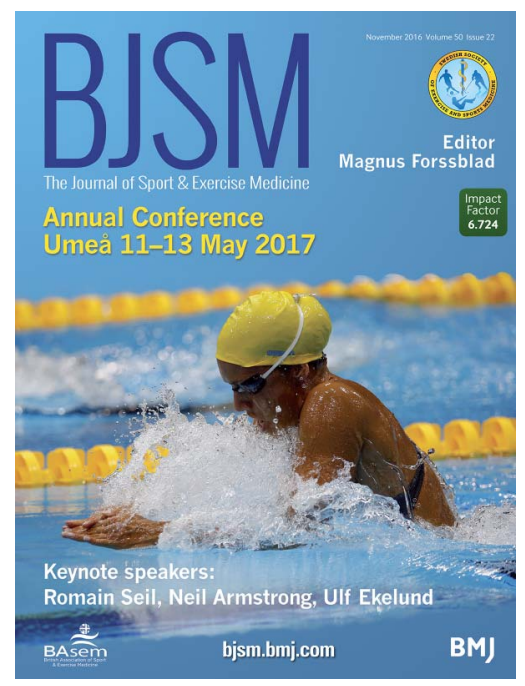

Figure 2 Swedish sports medicine.

Competing interests None declared.

Provenance and peer review Commissioned; internally peer reviewed.

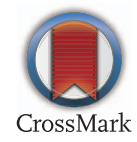

To cite Forssblad M, Khan K. Br J Sports Med 2016;50:1355.

Accepted 4 October 2016

Br J Sports Med 2016;50:1355.

doi:10.1136/bjsports-2016-097093

\section{REFERENCES}

1 Börjesson M, Forssblad M, Karlsson J. Looking back over 20 years of sports medicine prevention and treatment: progress, but still a lot to achieve. $\mathrm{Br}$ J Sports Med 2015;49:1421.

2 Van Brabandt H, Desomer A, Gerkens S, et a/Harms and benefits of screening young people to prevent sudden cardiac death. BMJ 2016;353:11156.

3 Bahr R. Why screening tests to predict injury do not work-and probably never will...: a critical review. $B r$ J Sports Med 2016;50:776-80. 